\title{
The Applicable Scope of China's Futures Legislation
}

\author{
Cheng Yong Liu \\ Beijing Institute of Technology, Zhuhai \\ Zhuhai, China 519088
}

\begin{abstract}
China's "Administrative Regulations on Futures Trading" have been facing many challenges in recent years, for example, the applicable scope is too narrow to cover OTC derivatives; secondly, the securities derivatives are under double jurisdiction of the Regulations and the "Securities Law", which has caused controversy on application of regulations. The legislative work of the "Futures Act" is proceeding in China, so the applicable scope of the "Futures Act" of China in the future shall be appropriate arranged based on fully understanding the market characteristics of futures and derivatives, that is, to "take the derivative contract of hedging risk mechanism" as its applicable scope, and include the OTC derivatives into management. For the issue of double jurisdiction of securities derivatives, it should be divided according to product characteristics, which means the "security-type" securities derivatives applicable to the provisions of the "Securities Law" and the "contract-type" securities derivatives are limited to "exchange traded product" or "OTC products with hedge risk trading mechanism" are provided by the "Futures Act" in the future.
\end{abstract}

Keywords-futures act; applicable scope; hedging risk; securities derivatives

\section{INTRODUCTION}

China's current "Administrative Regulations on Futures Trading" are facing the problems of narrow applicable scope and overlap with the "Securities Law" in the jurisdiction of securities derivatives, and has caused the limitations and conflict in application, which is enough to show the necessity of self-criticism for the regulations. The Financial and Economic Committee of the National People's Congress has initiated the amendment of the "Securities Law" and the legislative work of the "Futures Act" at the end of 2013. How should the applicable scope of the on-going legislative work of the "Futures Act" be properly arranged? How does it divide the work and coordinate with the "Securities Law"? These have become important issues. This paper is to discuss the conflict in the current legislation, and then confirm the applicable scope of the "Futures Act" in the future according to the characteristics of different financial markets, and take into account the coordination between the "Futures Act" in the future and "Securities Law".

\section{LIMITATIONS AND CONFLICT OF THE CURRENT LEGISLATION}

In the legal system of China's financial market, different department laws regulate the different financial markets, at present, the "Securities Law" and "Administrative Regulations on Futures Trading" respectively regulate securities and futures markets, and the two not only have different objectives, but are also different in the applicable scope. The current issues of the "Administrative Regulations on Futures Trading” are as follows:

- The applicable scope under Article 2 of the existing "Administrative Regulations on Futures Trading" is limited to the "floor" trading activities with standardized contract. Such narrow applicable scope not only fails to meet the needs of current market development, but also causes some problems 1 , for example: (1) The object of trade is listed and limited to futures contracts and options contracts. In the rapid future development of China's financial markets, it is difficult to meet the requirements of market innovation, such as forward products, exchange and structural products with one or more of the abovementioned features. (2) It can not explain the general characteristics of derivatives and their trades. When new products emerge in the financial markets, especially for atypical contracts or trades, it cannot determine whether product should be bound according to the content of Article 2 in the "Administrative Regulations on Futures Trading". (3) It cannot regulate "OTC" derivative trade, which is inconsistent with the regulatory trends in the world, and hinders China's financial derivatives market from connecting to the world.

- The applicable scope of different departmental laws is not properly coordinated, and the "securities derivatives" are subject to the double jurisdiction of the "Securities Law" and the "Administrative Regulations on Futures Trading", which leads to the overlap of applicable laws. There are many different types of securities derivatives in the market, such as stock futures (equity) and stock index futures (equity), etc., which have always been part of the applicable scope of "Administrative Regulations on Futures Trading", but the "Securities Law" also included the issuance and trading of securities derivatives in the applicable scope after the amendment in 2005. Therefore, the "securities derivatives" belong to the applicable scope of both the "Securities Law" and the "Administrative Regulations on Futures Trading",

\footnotetext{
Ye Lin, Zhong Wei: "Core Regulation and Extended Supervision: Definition of the Applicable Scope of China's 'Futures Act'", "Law Science Magazine". 2015-05, Page 48.
} 
besides, because they are different in framework and norms, there may be questions about the legal application of securities derivatives. Taking the legal application of inside trading activity as an example, the "Securities Law" and the "Administrative Regulations on Futures Trading" have different requirements for the insider trading. What requirement is applicable to the insider trading of the securities derivatives? Is the provision of the "Securities Law" on insider trading applicable to "security-type" securities derivatives, while the provision of the "Administrative Regulations on Futures Trading" on insider trading applicable to "contract-type" securities derivatives? These are doubts to be made clear.

\section{CONFIRM THE APPLICABLE SCOPE OF FUTURES LEGISLATION ACCORDING TO MARKET CHARACTERISTICS}

The Financial and Economic Committee of the National People's Congress has initiated the amendment of the "Securities Law" and the legislative work of the "Futures Act" at the end of 2013, emphasizing that the "Securities Law" and the "Futures Act" are the two basic laws of China's capital market. Their amendment and formulation will help to promote the healthy development of capital markets and better serve the real economy. The applicable scope of China's futures legislation should be divided based on the characteristics of securities and futures markets, and follow the futures market characteristics to indicate that China's futures legislation should take "derivatives contracts with hedge risk mechanism" as its applicable scope.

\section{A. Recommendations for Futures Legislation}

On the basis that China's legislators determine that the securities market and futures market are respectively legislated, in order to avoid the conflict of departmental laws, the legislators should seek the appropriate and logical market legal framework when setting up the departmental law. It is stated as follows:

- The applicable scope of China's futures legislation must be distinguished from the "Securities Law" clearly in order to avoid disputes. As there is difference in the trading structure between the securities and futures markets, as well as in the construction path of relevant legal system, once the applicable scope is wrong, it will lead wrong market laws to be applied to products and then various problems; even if the applicable scope may overlap in the norm, still it must be clarified in writing or the standard for how to divide the applicable law shall be specified.

- The applicable scope of China's futures legislation should be expanded and retain flexibility as far much possible in order to respond to new products that may emerge in the future. As the financial market has the characteristics of innovative development, the product may be updated at any time, especially there will be individualized products for the individual needs of customers, so as to avoid vacuum zone of the law. The applicable scope of market law should retain the flexibility to include new products in the market into the regulating object of laws to the utmost extent.

- The applicable scope of China's futures legislation should include the OTC market products to promote the healthy development of OTC market in the future. OTC derivatives are significantly different from exchange traded products, for it lacks the characteristics of "centralized trading" and "standardization"; it is negotiated by the trading parties themselves and directly traded, and the trading terms are agreed upon by the parties as needed, which belongs to individualized product. Although the overall size of China's OTC financial derivatives market is small at present, products like interest rate swap and foreign exchange swap have been developing rapidly in recent years; secondly, OTC financial derivatives market impacts the spot market as much as the floor financial derivatives market, in order to avoid the market risk and the harm to the market, it is also necessary to be included into the norms.

\section{B. The Characteristics of the Futures Market Is Different from the Securities Market}

The characteristics of the securities market are different from the futures (derivatives) market, including characteristics such as the right voucher, issuance procedures and basic functions of the exchange-traded products.

- The "right voucher" of the products in the two markets is not the same. The security in securities market is a right voucher ${ }^{2}$, which is held by the obligee and records the contents of the rights. In contrast, the derivative contract traded in the futures (derivatives) market itself is not a right voucher, but a contract recording double-level transaction structure. ${ }^{3}$

- The issuance procedure of the products in the two markets is not the same. The security in the securities market has the link of issuance; the derivatives contract in the futures (derivatives) market has no such link. The products traded in the securities market are issued by the listed company. The investors can only subscribe or trade the products after they issued to the market, and the number of securities traded in the market is limited to the total amount of the initial issuance. In contrast, the products in the futures market are not issued by a particular company, but are contracts negotiated by the exchange designers or the parties, and the system of fictitious transaction is adopted. Even if there is no existing base asset, it can be bought or sold.

\footnotetext{
2 Ye Lin: "Securities Law", China Renmin University Press, 2013, 4th edition, Page 16.

3 Zhong Wei: "Legal Structure of Double-level Object of Futures Trading", "Tsinghua Law Journal", 2015-4, Page 131-133; previous Note 5, Ye Lin, Zhong Weiyuan, Page 51.
} 
- The functions of the two markets are different. The main function of the securities market is investment and financing ${ }^{4}$, and to provide necessary funds for the development of the real economy. The issuers with the fund demand raise funds through by issuing securities, and the securities traders satisfy the investment demand through the transaction; in contrast, the basic function of the futures market mainly lies in risk management and price discovery. ${ }^{5}$

\section{Determine the Applicable Scope of the Futures Legislation according to the Characteristics}

The futures (derivatives) market is characterized by the fact that the traded products are contracts designed by the exchange or negotiated by the parties, and derived from the underlying assets, not the right voucher, whose primary purpose is to provide risk management and price discovery for the trading parties, and to take the system of fictitious transaction. Therefore, the products in the futures (derivatives) market are essentially derivative, occasional and open contracts, so China's futures legislation should take "derivatives contracts with hedge risk mechanism" as its applicable scope, which is described as follows.

- Futures (derivatives) products have the contract attribute. In addition to many scholars who have had this claim ${ }^{6}$, Article 3 of the "Measures for the Administration of Derivatives Trading of Banking Financial Institutions" amended by the China Banking Regulatory Commission in 2011, and Article 2 of the "Code for Trading Business of Financial Derivatives of Securities Companies" issued by China Securities Industry Association in 2013, have also stated that futures (derivatives) belong to financial contract.

- Futures (derivatives) products are derivative, which mainly means that the value of futures (derivatives) is derived from reference asset, underlying variable or other reference financial products, such as physical goods, currency, interest rates, equity, credit, weather, disaster and political events. Basically, any spot goods that can be traded can be the underlying asset of futures (derivatives) contract, but it is limited to liquidity and substitutability, otherwise it will not be able to price the underlying asset or calculate the value of the futures (derivatives) contract, which means it lacks the possibility of trading.

- Futures (derivatives) products are occasional, which means that the derivatives are essentially accidental contracts, and the remuneration of the parties to the

\footnotetext{
${ }^{4}$ Guo Feng: "Deepen the Understanding of the Basic Market Functions to Promote the Fair Law Enforcement and Scientific Legislation of the Securities Market", "Securities Law". 2015-01, Page 39-40.

5 Qi Ji: "Analysis on Development and Supervision of China's Financial Derivatives Market", "Modern Economic Information". 2014-17, Page 352

${ }^{6}$ Li Mingliang: "Study on Legal Attributes of Financial Futures Contract Centered on Stock Index Futures Contracts", "Politics and Law". 2008-05, Page 48-52; Li Mingliang, Shi Tingbo: "Several Thoughts of Commercial Thinking and Futures Market Legislation", "China Commercial Law Yearbook". 2013-00, Page 240.
}

contract depends on one (or a series of) external, future, uncertain event or (and) metric, besides, the parties have conflicting expectations with respect to the aforesaid uncertainties. Therefore, the trading parties in the futures (derivatives) market can not determine the possible result of future trading, and have difficulty to correctly estimate or cannot provide accurate data.

- Futures (derivatives) products are open. The applicable scope of China's futures legislation should include various futures (derivatives) contracts, and maintain flexibility and leniency as much as possible. Its basic categories include forward, futures, swap and options, as well as the structured products with one or several aforesaid characteristics, so as to comply with the innovative development of the financial market, and include the new products into the regulating object of law.

- $\quad$ Futures (derivatives) products are limited to hedging risk mechanism. Futures (derivatives) products are open, but not all contracts are included in the applicable scope, only limited to the futures (derivatives) contract taking hedging risk mechanism, and it is necessary to include the trades that will produce trading risk similar to the futures market into the norm. In detail, the hedging risk refers to conducting two trades in related market, opposite direction, equivalent quantity and balanced profit, which is the demand for futures market to manage risk function in practice, also the main characteristic of the futures market (floor trades), therefore, it is only necessary for (OTC) derivative contracts that take the hedging risk mechanism to apply the futures (floor) market legal framework. Secondly, the derivative contracts that take hedging risk mechanism are usually "standardized", but not limited to this; some "non-standardized" contracts themselves can not be hedged, but they can use "comparable standardized contractual terms" through the agreement between contracting parties, or trade in a similar centralized trading system or place arranged by the contractor. These OTC will result in trading risks similar to those in the futures market, which shall be included in the applicable scope of China's "Futures Act" in the future.

\section{COORDINATE THE JURISDICTION OF SECURITIES DERIVATIVES ACCORDING TO PRODUCT CHARACTERISTICS}

How to deal with the problem of dual jurisdiction of China's "Securities Law" and "Administrative Regulations on Futures Trading" on the securities derivatives? In fact, if we can coordinate the applicable scope of the "Futures Act" and "Securities Law", the jurisdiction of securities derivatives can be properly divided. In other words, from the perspective of discussing the applicable scope of China's futures legislation, if we take the issue whether financial products belong to "derivatives contract taking hedging risk mechanism" as the basis for judgement and division of legal applicable scope of 
securities and futures (derivatives) markets, we can solve the dispute of legal application of the dual jurisdiction.

\section{A. Distinguish Security-type Products and Contract-type Products}

China's "Futures Act" should take "derivatives contract taking hedging risk mechanism" as its applicable scope, as mentioned above. If the legal application of securities derivatives is determined on this basis, only the "contracttype" securities derivatives are "likely" to be included in the applicable scope of the "Futures Act", such as stock index options, stock index futures, treasury bond futures and stock futures; it is not necessary to include "security-type" securities derivatives, such as warrants, depository receipts and convertible corporate bonds, etc., in the applicable scope of the "Futures Act" because the hedging risk mechanism is not taken in their trade, and should be handed over to the "Securities Law" for application. However, although the contract-type securities derivatives are not a part of the applicable scope of the "Securities Law", they may not necessarily belong to the applicable scope of China's futures legislation, and only part of the contract-type securities derivatives are necessary to be included.

\section{B. The Application of Contract-type Products Shall Be Subdivided}

There is a wide variety of contract-type securities derivatives, but only the contract-type securities derivatives contract of "exchange trading" or "OTC with hedge risk trading mechanism" has to be included in the applicable scope of China's futures legislation.

- Contract-type securities derivatives, including exchange traded products such as stock index futures (equity), stock futures (equity) and treasury bond futures, are essentially derivatives contracts taking hedging risk mechanism; for the hedging risk mechanism derives from the demand for futures market to manage risks, it is also the main characteristic of floor trading, so the contract-type securities derivatives of floor trading are the most typical object of trade, and should be included in the applicable scope of the "Futures Act".

- In addition to trading in the futures market, the contract-type securities derivatives are more often traded in the curb market; the scale based on the OTC market increases, and the OTC contract-type securities derivatives taking hedging risk mechanisms should also be included in the applicable scope of China's futures legislation because their trading characteristics and risks similar to the floor trading.

- OTC trading may not all take the hedging risk mechanism. Unlike the situation of the floor trading, it only depends on the contracting party's needs and agreement. The trading risks and characteristics shown by OTC securities derivatives not taking the hedging risk mechanism are not the same as those of the floor market, so there is no need to apply the legal structure of the floor market.

\section{Determine the Attribution of Products according to Their Characteristics}

Different financial markets have different market framework and characteristics. When it cannot immediately be known whether a financial product should be regulated by the "Futures Act" or the "Securities Law", the attribution of the product may be judged according to its characteristics, such as the characteristics of right vouchers, issuance procedures and basic functions. Based on this position, securities derivatives such as warrants, depository receipts and convertible corporate bonds should belong to the applicable scope of the "Securities Law". First of all, all the three have the characteristic of "right vouchers", and they record contents of the rights and are held by the obligee. The holders of the warrant record have the option to trade underlying assets according to the agreed price and time; holders of depository receipt record are the owner of a certain amount of securities (stock or bonds); holders of convertible corporate bond record have the right to convert their bonds into the equivalent shares of the issuing company on a specified basis. Secondly, all the three have the characteristic of "issuing procedure". Warrants are issued by the issuing company of the underlying securities or a third party (such as securities companies, investment banks); depository receipts are the several transferable stock certificates issued by the depository bank; convertible corporate bonds are issued by the issuing company of a specific stock. Again, all the three have the characteristic of "investment and financing functions". The issuers raise capital through the issuance, and the holders meet the investment demand through the transaction.

\section{CONCLUSION}

In view of the limited application caused by the applicable scope of the current "Administrative Regulations on Futures Trading", and the overlap with the "Securities Law" in the applicable scope of the securities derivatives, such issues should be properly solved on the basis of market characteristics: (1) The applicable scope of futures legislation should follow the characteristics of the market. The futures (derivatives) market is clearly different from the securities market in terms of the right vouchers, issuing procedures and basic functions of the market trading products. Therefore, based on these market characteristics, China's futures legislation should take "securities derivatives taking the hedging risk mechanism" as its applicable scope. (2) The jurisdiction of the securities derivatives shall be coordinated according to the characteristics of the products. In terms of the characteristics of products, the market legal system of the "Securities Law" should be applied to the "security-type" securities derivatives; there are various "contract-type" securities derivatives though, the "Futures Act" cannot be applied to all. Only contract-type securities derivatives "exchange traded" or "OTC with hedge risk trading mechanism" have to be included in the applicable scope of China's futures legislation due to the same trading risks and characteristics. 


\section{REFERENCES}

[1] Ye Lin, Zhong Wei: "Core Regulation and Extended Supervision: Definition of the Applicable Scope of China's 'Futures Act'", "Law Science Magazine".

[2] Zhong Wei: "Legal Structure of Double-level Object of Futures Trading", "Tsinghua Law Journal", 2015-4.

[3] Guo Feng: "Deepen the Understanding of the Basic Market Functions to Promote the Fair Law Enforcement and Scientific Legislation of the Securities Market", "Securities Law". 2015-01.

[4] Qi Ji: "Analysis on Development and Supervision of China's Financial Derivatives Market", "Modern Economic Information". 2014-17.

[5] Li Mingliang: "Study on Legal Attributes of Financial Futures Contract - Centered on Stock Index Futures Contracts", "Politics and Law". 2008-05.

[6] Li Mingliang, Shi Tingbo: "Several Thoughts of Commercial Thinking and Futures Market Legislation", "China Commercial Law Yearbook". 2013-00. 